\title{
CULTURE DIFFERENCES AFFECT PERFORMANCE AND ASSESSMENT ACCEPTANCE OF CHINESE STUDENT
}

\author{
Regina Jokom \\ Hotel Management Program, Faculty of Economics, Petra Christian University \\ e-mail: regina@peter.petra.ac.id \\ Nathania Dewi Sutanto \\ e-mail: d_conquerers@hotmail.com
}

\begin{abstract}
Stenden University is an international hospitality management university in Leeuwarden, Netherlands which the major Asian student is from China. Thus, cultural differences might stimulate an influence towards Chinese students' daily performance and assessment acceptance. Throughout in-depth interview with the Chinese students, it reveals that there are some culture barriers for Chinese student during their practice. These affect in their basic skill, relationship, communication, and language. These matters also affect Chinese student's assessment acceptance that they tend to accept, even though they do not agreeing with their assessment.
\end{abstract}

Keywords: Cross culture, Asian, Dutch, international hospitality management university.

To manage a business organization effectivelly, an understanding of people and their values and assumptions are necessary. The values and assumptions of people are shaped by their culture. Although there are certain similarities among cultures, these cultural norms and values are not universal. The major problems in cross-cultural contacts arise when people lose sight of this 'cultural conditioning' and tend to think of their own cultural attitudes as being universally shared and as part of basic human nature.

Aforementioned statements are also occurred in Stenden University. Under the heading of 'Global Campus', the Stenden University is making good progress in developing into a university with an international character. Hence, most of the students are international students which come from Africa, America, Asia, Europe, Middle East, and Netherlands Antilles. Major Asian students are coming from China.

These students are also doing their practice at Stenden University, especially at Wyswert Hotel. At Wyswert Hotel there are several departments, such as: Facility department (La Salle a Manger and IF), Kitchen department, Restaurant and Bar department, Front Office department, and Housekeeping department. In each department, there are Practical Instructors as their supervisor, which undertake the assessment of students.

Interviews towards several Practical Instructors from each department have been done to perceive the cultural differences among the Chinese students.
Cultural differences might stimulate an influence towards Chinese students' daily performance and assessment acceptance. In the interview, it is found that most of the Practical Instructors encounter the difficulties towards the daily performance and assessment acceptance of the Chinese students.

Thus, this research is aimed to figure out the cultural differences which occured and affected Chinese students in Stenden University, the way of Chinese students adapt and encounter towards the cultural differences and to provide information to the next coming Chinese students and also the practical instructors regarding the influence of cultural differences.

\section{PROBLEM STATEMENT}

Taking the background into consideration, this is then decided that the problem which is going to be discussed in this research is "How do the cultural differences affect the performance and assesment acceptance of Chinese students during their practice in Stenden University". And the following subsidiary questions are constructed to help generate the answers

1. What is a cultural difference?

2. Why can cultural differences between Chinese and Dutch can affect the performance and assessment acceptance of the Chinese student during their practice in Stenden University?

3. How do cultural differences affect the Chinese students' performance and assessment during their practice in Stenden University? 
4. What are the things needed to be prepared by the Chinese students in order to encounter the cultural differences?

5. What are the Chinese students expectations to Stenden University regarding the difficulties which occurred because of the cultural differences?

\section{LITERATURE REVIEW}

\section{Culture}

Philip (1999, P.4) states culture is distinctly human capacity for adapting to circumstances and transmitting this coping skill and knowledge to subsequent generations. Culture gives people of sense of who they are, of belonging, of how they should behave, and of what they should do. Culture impacts behavior, morale, and productivity at work as well, and includes values and patterns that influence company attitudes and actions.

Harris (1996, p.125) divides culture characteristic into ten categories:

1. Sense of self and space. Culture can express differently about self-identity and appreciation. Some cultures are very structured and formal, while others are more flexible and informal. Some cultures can be close and determine one's place very precisely, while others are more challenging and open. Each culture validates self in unique way.

2. Communication and language. The communication system, verbal and non verbal, distinguishes one group to another. Apart from multitude foreign language, some nations have major spoken languages. Furthermore, the meaning given by gestures and body language, for example, often differ by culture.

3. Dress and appearance. This includes the outwards garments and adornments, as well as body decorations that tend to be distinctive by culture.

4. Food and feeding habits. The manner, in which food is selected, prepared, presented, and eaten are differed by cultures.

5. Time and time consciousness. Sense of time differs by culture: some are exact and some are relative. Time in the sense of seasons, varies by culture.

6. Relationships. Culture fixes human and organizational relationships by age, gender, status, and degree of kindred, as well as by wealth, power, and wisdom.

7. Values and norms. In any event, from its value system, culture sets norms of behaviour for the society.
8. Beliefs and attitudes. People in all cultures seem to have a natural concern for the supernatural that is evident in their religions and religious practices.

9. Mental process and learning. Some cultures emphasize one aspect of brain development over another, so that one may observe striking differences in the way people think and learn. Some cultures favour abstract thinking and conceptualization, while others prefer rote memory and learning. Each culture has a reasoning process and manifests in its own distinctive way.

10. Work habits and practices. Another dimension for examining a group's culture in their attitude toward work, the dominant types of work, the division of work, and the work habits and practices. Each culture can bring different work habits and practices.

\section{Cross Cultural Communication}

Cross-cultural communication is recognizing what is involved in one's image of self and one's role, personality needs, values, standards, expectations, all which are culturally conditioned. Such a person understand the impact of cultural factors on communication, and is willing to revise and expand such images as part of process of growth. Furthermore, he or she is aware of verbal and nonverbal differences in communication with person from another culture. Not only does such a person seek to learn another language but he or she is cognizant that even when people speak the same language, cultural differences can alter communication symbols and meanings and result in missunderstanding (Harris, 1999, p. 18).

\section{Fundamental Chinese Culture Orientation}

These are some characteristics of chinese culture:

1. Other-independent or other-dependent: Dependency upon others often takes the form of communal goals being achieved by many individuals repeating the same task over and over again.

2. Hierarchy-oriented or Egality-oriented: Hierarchy is honered through humility and saving face, this is done by "lowering", or minimazing, oneself. In fact, one makes more of oneself, and raise one's esteem in the eyes of others, by doing so.

3. Rule-oriented or relationship-oriented: The one dependable thing in the chinese world is the spiderlike network of relationship and obligation that one builds with others, usually friends and 
family. The Chinese, by taking care of a task, are obligating themselves futher with the other person, so that in the future, new action and claims for action can be made.

4. Monochronic or polychronic: Because punctuality also reflects other values, such as concern fot the other person and humility before someone else's effort, the Chinese are more or less punctual. The Chinese will move very quickly to seize an advantage if one presents itself, they certainly want to success as quick as possible, but they will not do anything that is not in their best interest simply because of time.

5. Risk-taking or risk-averse: Chinese is essentially a risk-taking culture. Chinese society is composed of numerous small enterpreneurs who will generally gamble and take risks when given the chance.

6. Past-oriented or future-oriented: Chinese place great stock in fortuitous moment, omens, superstitious practices, and guidance from ancestors, the stars, and sages.

7. Low-context direct or high-context indirect communicators: Context does drive communication in china, but it often allows for direct and confrontational speech. Nevertheless, the requirements of the essential fundamentals of the culture, such as confucian hierarchy, humility, respect, and face, require a sensivity to the context in which the communication occurs. Speaking symbolically allows one to say more easily what cannot be said directly.

8. Process-oriented or result-oriented: A connection is made to the way similar situations have turn out and in that sense, the Chinese also ised in a more associative, subjective logic. However, all forms of logic are used in the more holistic way in Asia, so that while process and experience are important step in arriving at a conclusion, the path may not be linear or progressive.

9. Formal or informal: The Chinese culture is formal and keeps the outsider out, when the one has earned respect and trust, and built enough a good relationship with important enough people, then one is on the inside, and action can be more spontaneous and informal.

10. Eye contact. Eye contact is generally indirect.

\section{Fundamental Dutch Culture Orientation}

On the other hand, these are some characteristics of dutch culture that differ from chinese:

1. Other-independent or other-dependent: The Dutch do value the individual, but the most highly regarded individuals are those who work in a cooperative, respectful, and nonconfrontation way with their peers, colleagues, superiors, and subordinates. Privacy is critical, and proximity does not presume friendship or business.

2. Hierarchy-oriented or Egality-oriented: It is important to respect hierarchy, but a bureaucracy with low productivity in not valued. Bosses need to earn respect of their subordinates, and subordinates need to be respectful of superior.

3. Rule-oriented or relationship-oriented: Rules and order are essential, however, extenuating circumstances and personal or social situations may justify a rethinking of the rules and processes. Treat people fairly and equally.

4. Monochronic or polychronic: The culture is mainly monochronic. Punctuality is important and the tardy person is regarded as someone who is not worthy of the responsibility he or she has been entrusted with.

5. Risk-taking or risk-averse: This is generally a risk-taking culture, but not without careful thought and consideration to all sides, participants, and details.

6. Past-oriented or future-oriented: The Dutch have a strong belief in their ability to accomplish things, once the correct approach has been identified.

7. Low-context direct or high-context indirect communicators: The Dutch are generally lowcontext communicators, with matter of factness, simplicity, and nonemotionally being hallmarks of their communication style.

8. Process-oriented or result-oriented: While the process for decision making is important, and details are critical, the Dutch also make decisions, as the English, based on precedent and what has been the successful method in the past.

9. Formal or informal: The Dutch combine both a healthy respect for certain formalities and a relaxed flexibility toward situation as they develop.

10.Eye contact. Eye contact can be intense and direct.

\section{METHODOLOGY}

A qualitative approach is chosen over a quantitative research. The qualitative approach to research will involve gathering a great deal of information about a small number of people rather than a limited amount of information about a large number of people.

According to the research purpose, in addition to the type of research questions that aforementioned, 
this research is classified as an exploratory research. This research will involve a development of detailed, intensive knowledge about wide array of social dimension through involving the contextual, dialogic, and self-reflexive dimensions. The major data collection are generated through key informant(s) and personal in-depth interview.

Population for this reasearch are Chinese students at Stenden University, Leeuwarden who were doing a practice module on module 4, 2008. The method of sampling used is theoretical sampling, which means selecting groups or categories to study based on their relevance to the research questions, theoretical positions, analytical practice, and the most importantly, the argument or explanation that is being developed. Sample will be selected based on data of international students from Stenden University. Within 36 populations, 16 Chinese students were chosen as respondent. And the interview was held from April $21^{\text {st }} 2008$ until June $22^{\text {nd }} 2008$. There was a question guideline for the interview, which contains 72 questions, divided in 8 main objectives (Profile respondent, knowledge about Dutch culture, school impression, relationship with Dutch, differences in basic skill, communication and relationship during practice, assessment acceptance, and recommendation for the next coming Chinese students). This guideline excludes follow up questions, which can appear during interviews and for approximate 45 minutes until half-hour range.

\section{FINDINGS}

The reason why the Chinese students entered hotel school is related to their future dream, in which they would like to work under hospitality industry. Since most of them did not have any background study related to this subject, so they expect to gain experience through practice. For those who already have experience, they would like to learn concept or theory to develop their management skill.

Taking pattern of sources of information from Foster, it was also discovered that parents has a lot of influence in deciding the future dream for the Chinese, this is because culture value of otherdependent. From value and norm in China, the Chinese believe that if they have education in Europe, it will help them to achieve their future dream.

Another fact is differences culture characteristic in food and feeding habit and time and time consciousness makes them experience culture shock about the weather, working hour of the shops, public transportations system, and the food. So they cook by themselves or even brought food from China.

The research also reveal that the Chinese students like to make friends with the Dutch, because it is useful for them to learn the different cultures. On the other hand, it is also difficult for them to become close friends because of the culture barrier. Before arrival in netherlands, mostly they have a Chinese contact person which can give them useful information. The students prefer to know their buddy or host before they arrive so that they can make advance contact and they can get the culture overview. Also it is better for them that they can choose their own buddy or host.

The analysis shows that the Chinese are good in theory part, because it is rare for them to have working experience. It takes sometime for them to adapt, especially with the F\&B department, which has a lot of cultural influence during practice, such as the ingredients,etc. They have some knowledge about food an beverage in netherlands but still not enough because they don't have special classes for it.

Another interesting fact is Chinese students could pass the IELTS test but it doesn't guarantee that they don't have any problem with communication. Because they are not good in oral English, so they can not express their feelings or opinion easily. At the end, they decided to keep everything for themselves. An other reason that cause communication problem is that the Chinese tend to avoid confrontation or argue. In the relationship with their supervisors, they tend to follow, so that it doesn't cause problem.

On the other hand, some of the Chinese feel that the Dutch has bigger chance to get higher points than them. This is because of the Dutch is more familiar with the environment, since they grew here, and most of them also have working experiences. Compared to the Chinese, which are commoners, it is difficult to get familiar with the environment. Concrete example: Dutch food. The Dutch is more familiar with it since they also know the real taste of the food and how to make it. But it is not the same with Chinese. Even though they have lived for some time here, some of them only know the taste, but do not know how to make the food. Most of the Chinese prefer to eat and cook the food from their own country, since the taste is also familiar to them. Thus, the Dutch are one step ahead the Chinese. That is why the Chinese feel unfair.

Eventhough school has already arranged enough things to welcome the Chinese, but should be more detailed in giving information about everything. For example: the country, how the machines works at 
school (copy machine, coffee machine, and recharge machine for student card credit).

\section{CONCLUSION}

Throughout research interview with the Chinese students, it can be concluded there are certain cultures, which can affect the Chinese students performance and assessment acceptance.

Culture barrier that they had during practice are about the food and feeding habits, values and norms, also working habits and practices; especially they did their practice in different country. These culture barriers occurred within their basic skills. For examples: different cooking methods, food and drinks, ingredients, and lack of working experience.

Other barriers are about relationship, communication, and language. These affect on their difficulties of performing opinions, such as: difficulties to speak English. They are more hierarchy oriented and relationship oriented, which means they see their supervisors as a patent- figure, make them tend to follow. The Chinese students also avoid conflict or argue with their colleagues or supervisors, because they are afraid that a conflict will affect their relationship. These matters also affect their assessment acceptance that they tend to accept, even though they do not agreeing with their assessment.

\section{RECOMMENDATION}

The result of this study provides recommendations, both to school and to the Chinese students. Stenden University must provide special classes to the Chinese students about product knowledge, especially things that they have to deal with during practice, for examples: ingredients, cooking methods, and oral English practice.
These classes will make them start practice in the same level with the Dutch. School can also show the students on how the machine works, for example: copy machine, coffee machines, and re-charge machine for student card credits. The next coming Chinese students have to learn from somebody else's experiences, prepare their English especially oral English, and learn some general Dutch words.

Since this research has some weak points in methodology, for the further research, it is suggested that the data analysis should use quantitative method to show the effect of culture differences towards student behaviour in international hospitality management university or international hotel school.

\section{REFERENCES}

Anselm, S. and Corbin, J. (1990). Basics of Qualitative Research. London: Sage.

Cooper, D. R. and Schindler, P. S. (2004). Business Research Methods ( $8^{\text {th }}$ Edition). New York: McGraw-Hill.

Fitzgerald, H. (1998). Cross-cultural Communication for the Tourism and Hospitality Industry. Melbourne: Hospitality-Press.

Foster, D. (2000). The Global Etiquette Guide to Asia. USA: John Wiley \& Sons.

Foster, D. (2000). The Global Etiquette Guide to Europe. USA: John Wiley \& Sons.

Hair, J. F.; Bush, R. P.; Ortinau, David J. (2003). Marketing Research. ( $2^{\text {nd }}$ Edition). New York: McGraw-Hill.

Harris, P.R. and Moran R. T. (1999). Managing Cultural Differences. ( $5^{\text {th }}$ Edition). USA: Gulf Professional Publishing.

Mason, J. (2002). Qualitative Researching. $\left(2^{\text {nd }}\right.$ Edition). London: Sage.

Veal, A.J. (1997). Research Methods for Leisure and Tourism, $\left(2^{\text {nd }}\right.$ Ed $)$. England: Pearson Education Limited. 